\title{
Comparative histopathology and immunohistochemistry of human and canine mammary tumors
}

\author{
Munsef A. Al-Mansour ${ }^{1}$, Mahir A.G. Kubba ${ }^{2,}$, Seham A. Al-Azreg ${ }^{2}$ and Sausen A. Dribika ${ }^{3}$ \\ ${ }^{1}$ Institute of Tripoli for Medical Sciences, Tripoli, Libya \\ ${ }^{2}$ Department of Pathology, Faculty of Veterinary Medicine, University of Tripoli, Libya \\ ${ }^{3}$ Central Pathology Laboratory, Tripoli Medical Center, Tripoli, Libya
}

\begin{abstract}
This study aimed at establishing aspects of comparison between canine and human mammary gland tumors. In order to achieve that, 44 specimens of canine mammary tumors and 70 specimens of human breast tumors were examined in order to state points of similarity in morphology, cells of origin, behavior and existence of tissue markers. We found that the ratio of benign to malignant forms was $4.5 \%$ to $95.5 \%$ in canine samples and $45.7 \%$ to $54.3 \%$ in human samples. In both species, malignant tumors composed of infiltrating ductal cells were in the forefront despite dissimilarity in nomenclature. Other kinds of lower rate of existence included, invasive micro-papillary carcinoma, mucinous carcinoma and invasive comedo-carcinoma which have displayed similar morphology and terminology in both species. Chondroid and squamous differentiation were found in human and canine specimens. In human samples, fibro-adenoma mounted up to 30 out of 32 benign tumors (93.8\%). Her-2 and Ki-67 were detected in the specimens of both species but ER was detected in human specimens only. Our findings suggest a significant degree of resemblance between certain mammary tumor in canine and human. Such findings are in support of employing dogs in research investigation for human mammary tumors.
\end{abstract}

Keywords: Breast tumors, Canine mammary tumors, Comparative pathology, Immunohistochemistry.

\section{Introduction}

Breast cancer is the second most common cancer in the world and the most frequent cancer among women with an estimated 1.67 million new cancer cases diagnosed in 2012 (25\% of all cancers). It is more common in the more developed Western countries than in Africa, South America and Asia. Incidence rate ranges from 27 per 100,000 in Middle Africa and Eastern Asia to 96 in Western Europe. Breast cancer ranks as the fifth cause of death from cancer overall (522,000 deaths) and while it is the most frequent cause of cancer death in women in less developed regions (324,000 deaths, $14.3 \%$ of total), it is now the second cause of cancer death after lung cancer in more developed regions (198,000 deaths, $15.4 \%$ ). The range in mortality rates between world regions is less than that for incidence because of the more favourable survival from breast cancer in (high-incidence) developed regions (Ferlay et al., 2015). In Western Libya, breast cancer comprised the commonest type of tumors in females and contributes to $33 \%$ of all female cancer (Abussa, 2007) while it ranged from $23 \%$ (El Mistiri et al., 2007) to $37.4 \%$ (Bodalal et al., 2014) in Eastern Libya.

Several factors have been implicated in the pathogenesis of breast cancers. These included some primary risk factors including sex and age in addition to other potential risk factors like genetics, family history, diet, alcohol, obesity, lack of breastfeeding as well as disturbances in certain hormones. Other contributing factors are mammographic density and previous benign disease (Dabbs, 2012). However, any factor predominance has not yet been determined (Abdulkareem, 2013). Immuno- histochemical studies of breast cancer emerged during the 1980s (Hsu et al., 1981) and since then, many types of specific and nonspecific glycoprotein molecular markers have been specified and located. These tissue markers were essential for the assessment of neoplastic existence, aggressiveness and prognosis (Haga et al., 1991; Callahan, 1992; Press et al., 1997; Lichtenbeld et al., 1998).

Research work concerning human mammary neoplasia and other related issues has largely been dependent on mouse models and cell lines. However, the proximity between canine and human species has encouraged scientist to introduce dogs as an alternative model for comparative cancer research projects. Hawai et al. (2013) and Sultan and Ganaie (2018) have reviewed many factors in favor of adopting dogs. These included a homologous genome sequence, genetic diversity, spontaneous growth of tumors, common living environment and many others. Queiroga et al. (2011), Mol (2013) and Carvalho et al. (2016) have also mentioned the existence of similar pathways involved 
in tumorigenesis, common tissue markers with close immunohistochemical analysis along with similar role of inflammatory cells in tumor microenvironment. Comparative investigations concerning mammary tumor morphology and taxonomy in dogs and human have been continual over the last few decades (Nerurkar et al., 1989; Sorenmo et al., 2009; Cassali, 2013). Promoting studies however, are essential in supporting available information in order to elucidate ambiguities in the nature, versions and behavior of canine mammary tumors. Such research projects would facilitate adopting dogs as an ideal experimental model.

\section{Materials and Methods}

Specimens of forty four (44) canine mammary tumors and 70 breast tumors were embodied in this study. The canine samples belonged to 30 female dogs and were collected from the departmental stock (Department of Pathology, Faculty of Veterinary Medicine, University of Tripoli) and from cases admitted to the faculty over the period of conducting this study. The human samples on the other hand, consisted of stained tissue sections of breast tumors prepared by the "Central Pathology Laboratory" at Tripoli Medical Center (TMC). The last 70 cases registered in 2013 were selected to insure random sampling.

All specimens were stained with $\mathrm{H} \& \mathrm{E}$ and some were immunostained for ER, HER-2 and $\mathrm{Ki}-67$ by Peroxidase-antiperoxidase (PAP) method. Immunostaining was carried by Ventana BenchMarkXT Automated Staining System using Ventana monoclonal primary antibodies ready to use for ER (Mouse monoclonal antibodies, clone SP1), HER-2 (Rabbit monoclonal antibodies, clone 4B5) and Ki-67 (Rabbit monoclonal antibodies, clone 30-9) for 30 minutes. This was followed by incubation for 30 minutes with a ready-to-use secondary antibody (Dako REALTM EnVisionTM/Horseradish Peroxidase, Rabbit/Mouse) and with the substrate Dako REALTM Diaminobenzidine with Chromogen for a further 10 minutes.

Freshly collected canine mammary samples were fixed in $10 \%$ neutral buffered formalin (NBF) for $48 \mathrm{hrs}$, dehydrated in ascending concentrations of Ethyl alcohol, cleared in xylol then dipped in paraffin wax. Sections of $5 \mu \mathrm{m}$ were mounted on frosted-end glass slides for staining with Hematoxyline and Eosin (H\&E) (Lillie, 1965) and on charged slides for immunestaining of ER, Ki67 and HER-2. The later was carried out by "Leica Microsystems Bond MAX System" (Leica Microsystems) and sections of different types of tumor and best sectional quality were selected. Sections were incubated in $72^{\circ} \mathrm{C}$ and treated with Bond Dewax Solution (Leica Microsystems). Epitope retrieval was performed by incubating the slides in Bond Epitope Retrieval Solution 1 (Citrate based pH 6.0 solution) for ER and Ki67, and Bond Epitope Retrieval Solution 2
(EDTA based $\mathrm{pH} 9.0$ solutions) for HER2 for 20 minutes at $100^{\circ} \mathrm{C}$. Sections were then blocked for endogenous Peroxidase in 3\% hydrogen peroxide for 5 minutes and were incubated with primary antibodies of ER (Clone 6F11, Novocastra laboratories), HER-2 (Clone CB11, Novocastra laboratories) and $\mathrm{Ki}-67$ (Clone MM1, Novocastra laboratories) for 15 minutes at room temperature. Primary antibodies were monoclonal mouse anti-human and were used at a dilution of 1:50, 1:700 and 1:200 respectively. Post Primary Polymer (Leica Microsystems) was applied for 8 minutes followed by Polymer Poly-Horseradish Peroxidase (Leica Microsystems) for another 8 minutes then Diaminobenzidine chromogen (DAB) for 10 minutes.

Sections were counterstained for 10 minutes. Wash solution and de-ionized water were used between the main steps (Qiu et al., 2010). Specimens of human invasive ductal carcinoma were adopted as positive control. Specific staining of any intensity was considered positive. Canine tumors were classified according to Goldschmidt et al. (2011) while human tumors according to WHO adopted classification of Tavassoli and Devilee (2003).

\section{Results}

Examination of the canine specimens revealed the existence of a majority of malignant over benign conditions $(95.5 \%: 4.5 \%)$ of which, carcinomas were predominant. Specimens of benign tumors included a case of mixed mammary tumor and a glandular hyperplasia (Table 1).

Carcinomas were also predominant among human malignancies but the malignant to benign ratio was close $(45.7 \%$ to $54.3 \%$ ) (Table 2 ). Invasive ductal carcinoma (IDC) was most frequently diagnosed among other types of carcinoma (71\%) while fibroadenoma constituted about (94\%) of the benign tumors.

Microscopic examination of tumor samples in canine and human specimens reflected the existence of a remarkable resemblance in the origin, distribution and behavior of neoplastic tissue. This was particularly obvious between 'simple tubular carcinoma' in dogs and 'invasive ductal carcinoma' in human in which epithelial neoplastic cells accumulate and break through the walls of the glandular ductules into the surrounding stroma (Fig. 1A and 1B). Individual and clustered neoplastic cells usually elicit desmoplastic reaction and often invade nearby lymphatics. Other neoplastic forms have also demonstrated similar orientation as in comedo-carcinoma when the center of cellular clusters whether in or out of ductules undergo necrosis and dissolution (Fig. 1C and 1D). Mucinous carcinoma characterized by mucin-secreting neoplastic cells and mucin-filled cavities were also demonstrated in canine and human specimens (Fig. 1E and 1F). 
Table 1. Types, number and ratio of canine mammary tumors.

\begin{tabular}{lcc}
\hline Types & No. & $\%$ \\
\hline Malignant tumors & 42 & 95.5 \\
\hline Complex carcinoma & 7 & 16.7 \\
\hline Tubular carcinoma & 7 & 16.7 \\
Cystic papillary carcinoma & 6 & 14.3 \\
\hline $\begin{array}{l}\text { Malignant mixed mammary } \\
\text { tumors }\end{array}$ & 5 & 11.9 \\
Invasive micropapillary & 3 & 7.1 \\
carcinoma & 3 & 7.1 \\
Solid carcinoma & 3 & 7.1 \\
\hline $\begin{array}{l}\text { Carcinoma and malignant } \\
\text { myoepithelioma }\end{array}$ & 3 & 7.1 \\
\hline Fibrosarcoma & 2 & 4.8 \\
\hline Tubulopapillary carcinoma & 2 & 4.8 \\
\hline $\begin{array}{l}\text { Carcinoma arising in benign } \\
\text { mixed mammary tumor }\end{array}$ & 1 & 2.4 \\
\hline Mucinous carcinoma & 2 & 4.5 \\
\hline Benign tumors & 1 & 50 \\
\hline Benign mixed mammary tumor & 1 & 50 \\
\hline Hyperplasia & & \\
\hline
\end{tabular}

Table 2. Types, number and ratio of human breast tumors.

\begin{tabular}{lcc}
\hline Types & No. & $\%$ \\
\hline Malignant tumors & 38 & 54.3 \\
\hline Invasive ductal carcinoma & 27 & 71.1 \\
\hline Ductal carcinoma in situ & 3 & 7.9 \\
\hline $\begin{array}{l}\text { Inflammatory mammary } \\
\text { carcinoma }\end{array}$ & 2 & 5.3 \\
Invasive micropapillary & 2 & 5.3 \\
carcinoma & 1 & 2.6 \\
Invasive lobular carcinoma & 1 & 2.6 \\
Mucinous carcinoma & 1 & 2.6 \\
\hline Cribriform carcinoma & 1 & 2.6 \\
\hline Malignant Phyllodes tumor & 32 & 45.7 \\
\hline Benign tumors & 30 & 93.8 \\
\hline Fibroadenoma & 1 & 3.1 \\
\hline Intraductal Papilloma & 1 & 3.1 \\
\hline Benign Phyllodes & & \\
\hline
\end{tabular}

The highly invasive micro-papillary carcinoma characterized by small cellular papillae arising from ductular lining epithelium were also noticed in both human and canine specimens (Fig. $1 \mathrm{G}$ and $1 \mathrm{H}$ ). Squamous metaplasia with the formation of loose nests is one of the transitional changes in carcinoma noticed in both species (Fig. 1I and 1J).

Chondroid differentiation was noticed in mixed mammary tumor in canine and following metaplastic changes in human breast. Chondrosarcoma was recognized in a human specimen (Fig. $1 \mathrm{~K}$ and $1 \mathrm{~L}$ ) while fibrosarcoma was not un-common in both species (Fig. $1 \mathrm{M}$ and $1 \mathrm{~N}$ ).

Immunohistochemical detection of specific hormonal marker receptors has also shown resemblance in some aspects. HER-2 (Fig. 2C and 2D) and Ki-67 (Fig. 2E and $2 \mathrm{~F}$ ) were demonstrated in comparable locations in the specimens of both species but ER active sites were not stainable in canine sections (Fig. 2A and 2B).

\section{Discussion}

The present investigation included 44 canine specimens taken from 30 bitches with single and Multicentric (Multiple) mammary tumors. These specimens were collected from different breeds among which, Mixed breed, German Shepherd and Yorkshire Terrier were predominant. These breeds of dogs were also found to possess high incidence of mammary tumors in other studies (Gupta et al., 2012).

The age predisposition in the current study ranged from 3-14 years. Age distribution however, was almost even and showed no predominance probably due to the small size of the sample. This wide range of age predisposition however, is in general agreement with other studies which estimated it at 4-15 years with a median of 8-10 years (Yang et al., 2006; Morris et al., 2009).

Malignant tumors constituted $41 \%$ and $53 \%$ by Misdorp et al. (1999) and Lana et al. (2007) respectively. In beagles however, malignant tumors constituted $34 \%$ in a survey carried on 4755 dogs (Benjamin et al., 1999). They justified that level of existence to the late stage of tumor removal and/or to the high number of intact females as well as to the older age of spaying. The extremely high level of existence of malignancies in the current study which has mounted to $95.5 \%$ does not really reflect the actual situation.

Benign tumors in general, are not accurately registered probably because they are overlooked for their small un-palpable size or because they do not represent a real threat to the animals.

The medical history of most of our cases was deficient and did not provide sufficient information about spaying, number of intact females or medical attention. The small size of the sample and late recognition of tumors may also justify the higher existence of malignancy. The high incidence of carcinomas demonstrated in this sample agrees well with Misdorp et al. (1999) and Misdorp (2002) who recognized an overwhelming predominance of carcinomas over sarcomas and carcinosarcomas in dogs mammary gland.

On the other hand, the ratio of benign to malignant tumors in human breast agreed with those stated in India which ranged between $50.4 \%$ and $49.6 \%$ out of 252 specimen (Mudholkar et al., 2012). 

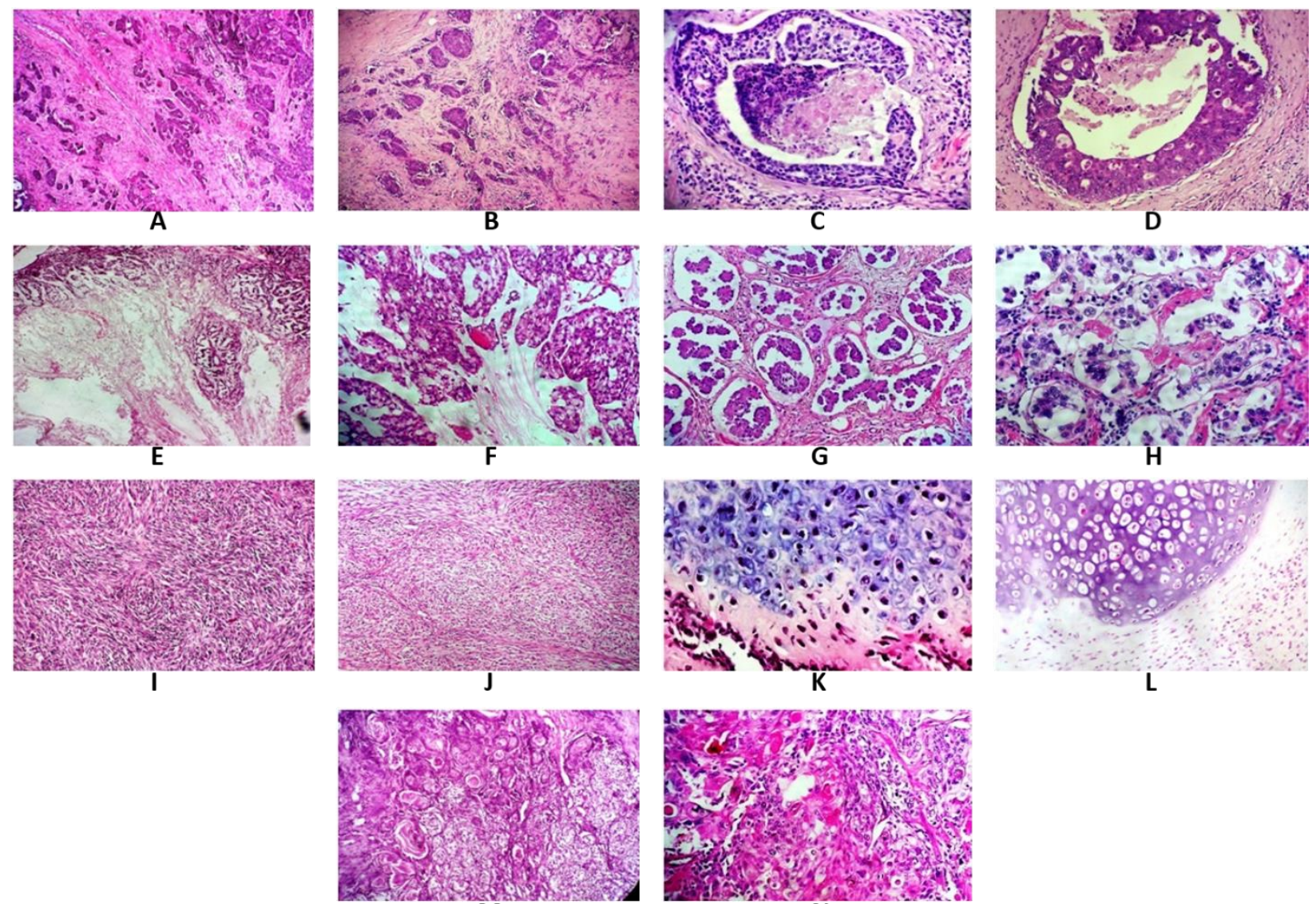

M

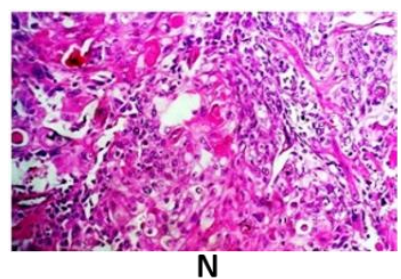

Fig. 1. (A and B): Invasive carcinoma: Infiltration of individual and clumps of malignant cells in the stroma (100x). (C and D): Comedo-carcinoma: Intraductular dissociation and accumulation of necrotic epithelium (400x). (E and F): Mucinous carcinoma: Profuse mucin secreting neoplastic epithelium (200x). (G and H): Invasive micropapillary carcinoma: neoplastic cellular papillae arising from lining epithelium (G: 200x; H: 400x). (I and J): Carcinoma with squamous metaplasia (200x). (K and L): Chondroid differentiation in the stroma (K: 400x; L: 200x). (M and N): Fibrosarcoma: Criss-crossing bundles of intense fibroplasia (200x) (Stain: H\&E). (A, C, E, G, I, K, M = Canine). (B, D, F, H, J, L, N = Human).

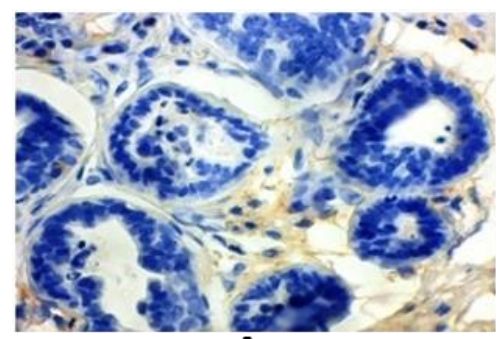

A

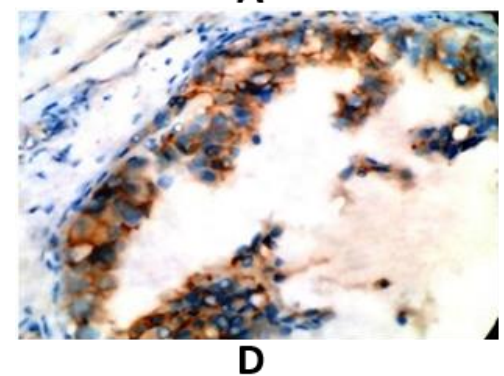

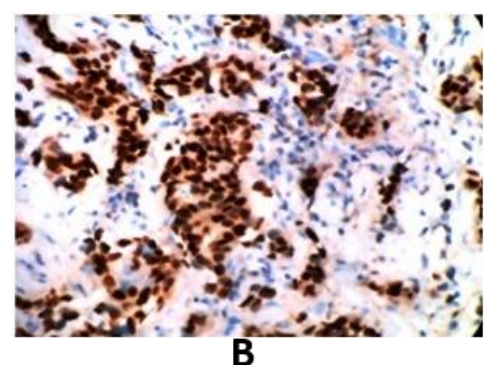

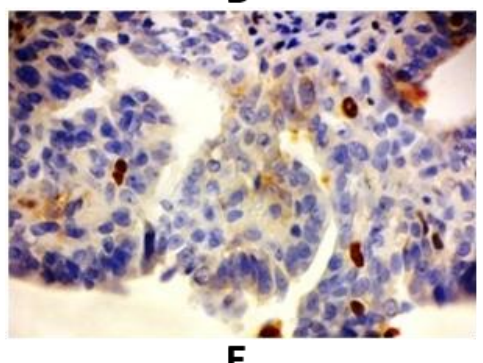

E

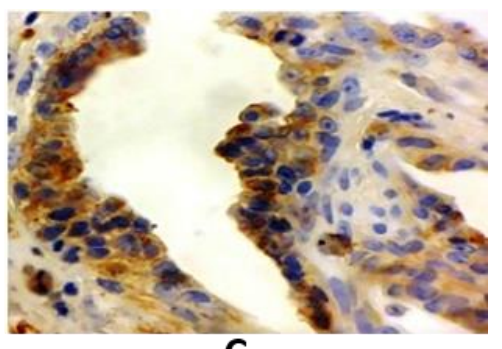

C

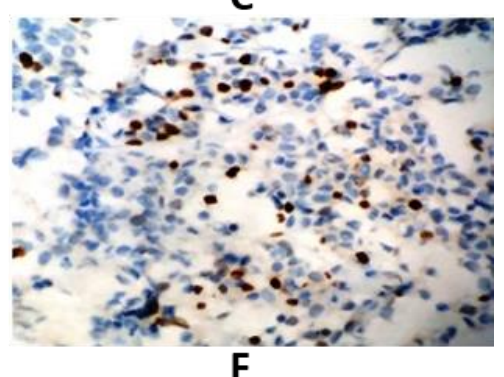

Fig. 2. (A): Negative nuclear ER staining. (B): Positive nuclear ER staining. (C and D): positive membranous staining of HER-2.

(E and F): Positive nuclear staining of Ki-67. (Stain: PAP, 400x). (A, C, E = Canine). (B, D, F = Human). 
Lower ranges of 10-31\% for malignant and 70-90\% for benign however were found in the United States following three investigations which employed different methods of examination (Stavros et al., 1995). IDC among other kinds of carcinoma has also represented a majority in breast cancer in this study while fibroadenoma was predominant in the benign group.

Involvement of more than one mammary gland in dogs is not uncommon and was reported in this study as well as in others (Misdorp et al., 1999; Funakoshi et al., 2000; Reddy et al., 2009; Kumar et al., 2010). Multicentric mammary tumors are usually an issue of older dogs which suffer from medical negligence. The existences of tumors which descend from different cells of origin in adjacent glands suggest an independent primary tumor growth. Such diversity in multicentric tumors was reported by others who demonstrated different combinations of mesenchymal as well as epithelial origin (Misdorp et al., 1999; Funakoshi et al., 2000; Reddy et al., 2009; Kumar et al., 2010). The existence of similar tumors in adjacent glands can result from spontaneous development or metastasis.

Bilateral breast cancers were not recorded in this study but were reported by Janschek et al. (2001) and Bassarova et al. (2005) who referred that to simultaneous or following metastasis from contralateral gland. The generation of microvascular channels which promote metastasis by malignant tumor cells 'Endothelial-like cells' (ELCs) without endothelial cell participation has been reported in human and canine mammary cancers (Clemente et al., 2010).

The existence in this study of canine mammary tumors possessing histological features that belong to more than one subtype is a matter of controversy. Misdorp et al. (1999) and Goldschmidt et al. (2011), listed these subtypes as an independent entity. Others, (Benjamin et al., 1999) however, have pointed out to the possibility of transition from one kind into another, such as transition of solid carcinoma into papillary or comedocarcinoma. On the other hand, Moulton et al. (1970) have demonstrated an adverse kind of transition in which papillary or lobular carcinoma are turned into solid carcinoma. Transition was also reported in human breast tumors and is thought to be stimulated by the frequency of cell proliferation, apoptosis and necrosis (Boghaert et al., 2014).

In the current study, the main aspect in comparison between canine and human mammary gland tumors is the morphological orientation of neoplastic cells. Cells of origin, cell configuration and transitional forms were comparable in the specimens of both species despite differences in terminology. Sinn and Kreipe (2013) taxonomy which is adopted by the WHO has included Solid, Cribriform and Papillary cellular orientation as transitional forms of invasive carcinoma of 'No Special Type' (NST). In canine on the other hand, these forms are considered as independent entities by latest taxonomies (Misdorp et al., 1999; Goldschmidt et al., 2011). Other kinds of tumors including Mucinous carcinoma, Invasive micropapillary carcinoma and comedo-carcinoma possess similar morphology and terminology in both species.

Mixed mammary tumors in dogs comprised of mesenchymal and epithelial components have their counterpart in humans. In dogs, these tumors can be benign when bone and/or cartilage components are metaplastic or considered malignant when these elements carry malignant features. In human, this form is permanently metaplastic (Metaplastic carcinoma) except for phyllodes in which malignant mesenchymal differentiation exist. Inflammatory carcinoma and invasive cribriform carcinoma which were diagnosed in our human specimens have also their counterpart in canine although they were not noticed in our samples. The localization of HER-2 and Ki-67 markers at similar sites in the mammary tissue of both species indicate the existence of common aspects in immunohistochemical characteristics. These findings are in accordance with previous information about the existence of such markers in canine and the variation in their intensity (Nowak et al., 2005; Joensuu et al., 2013; Peña et al., 2014; Zaha, 2014). The remarkable absence of ER staining is not well understood, but Peña et al. (2014) justified that on the basis of delayed or inadequate fixation, usage of different monoclonal antibodies raised against human ER or due to the application of different heat antigen retrieval protocols. Qiu et al. (2010), found an inverse correlation between prolonged formalin fixation and intensity of ER receptors expression while others (Webster et al., 2009), suggest that prolonged formalin fixation has minimal effects on antigen detection for most commonly used antibodies. Our attempts have not succeeded despite several attempts with short and prolonged fixation periods. ER, HER-2 and Ki-67 were particularly chosen for their availability and for being in current use in research and for medical purposes.

This investigation declared an encouraging degree of resemblance between certain tumors in human and canine. These tumors were found similar in different ways including their cellular origin, morphology, behavior and some markers localization. These findings add additional support for previous investigations in the same field which aim at introducing dogs as an ideal experimental model for studying mammary tumors in human.

\section{Acknowledgments}

The authors are grateful for the valuable assistance of Dr. Muneir Sherif, professor of pathology, Faculty of Veterinary Medicine, University of Omar Al-Mukhtar 
in Libya for providing samples of canine mammary tumor. We are also indebted for the valuable contribution of the staff in Al-yamama Veterinary Clinic in Tripoli. This article is part of a Master Thesis conducted by Munsif Al-Mansour at the Department of Pathology, Faculty of Veterinary Medicine, University of Tripoli, Libya.

\section{Conflict of interest}

The Authors declare that there is no conflict of interest.

\section{References}

Abdulkareem, I.H. 2013. A review on aetiopathogenesis of breast cancer. J. Genet. Syndr. Gene Ther. 4, 142. doi:10.4172/21577412.1000142 .

Abussa, A. 2007. Hospital cancer registry annual report 2006. Sabaratha, Libya: African Oncology Institute, pp: $18-20$.

Bassarova, A.V., Torlakovic, E., Sedloev, T., Hristova, S.L., Trifonov, D.Y. and Nesland, J.M. 2005. Simultaneous bilateral breast carcinoma: Histopathological characteristics and CD44/catenin-cadherin profile. Histol. Histopathol. 20, 791-799.

Benjamin, S.A., Lee, A.C. and Saunders, W.J. 1999. Classification and behavior of canine mammary epithelial neoplasms based on life-span observations in beagles. Vet. Pathol. 36(5), 423436.

Bodalal, Z., Azzuz, R. and Bendardaf, R. 2014. Cancers in Estern Libya: First results from Benghazi Medical Centers. World J. Gasteroenter. 20(20), 6293-6301.

Boghaert, E., Radisky, D.C. and Nelson, C.M. 2014. Lattice-based model of ductal carcinoma in situ suggests rules for breast cancer progression to an invasive state. PLoS Comput. Biol. 10(12), e1003997. doi: 10.1371/journal.pcbi.1003997.

Callahan, R. 1992. p53 mutations, another breast cancer prognostic factor. J. Natl. Cancer Inst. 84, 826-827.

Carvalho, M.I., Silva-Carvalho, R., Pires, I., Prada, J., Bianchini, R., Jensen-Jarolim,E. and Queiroga, F.L. 2016. A comparative approach of tumor-associated inflammation in mammary cancer between humans and dogs. Biomed Res. Int. 2016: 4917387. doi: 10.1155/2016/4917387.

Cassali, G.D. 2013. Comparative mammary oncology: Canine model. BMC Proc. 7 (Suppl. 2:K6). doi: 10.1186/1753-6561-7-S2-K6.

Clemente, M., Perez-Alenza, M.D., Illera, J.C. and Peña, L. 2010. Histological, immunohistological, and ultrastructural description of vasculogenic mimicry in canine mammary cancer. Vet. Pathol. 47(2), 265-274.

Dabbs, D.J. 2012. Breast pathology, $1^{\text {st }}$ ed., Elsevier, Saunders.
El Mistiri, M., Verdecchia, A., Rashid, I., El Sahli, N., El Mangush, M. and Federico, M. 2007. Cancer incidence in Estern Libya: the first report from Benghazi Cancer Registry, 2003. Int. J. Cancer. 120, 392-397.

Ferlay, J., Soerjomataram, I., Dikshit, R., Eser, S., Mathers, C., Rebelo, M., Parkin, D.M., Forman, D. and Bray, F. 2015. Cancer incidence and mortality worldwide: sources, methods and major patterns in GLOBOCAN 2012. Int. J. Cancer 136(5), E359386. doi: 10.1002/ijc.29210.

Funakoshi, Y., Nakayama, H., Uetsuka, K., Nishimura, R., Sasaki, N. and Doi, K. 2000. Cellular proliferative and telomerase activity in canine mammary gland tumors. J. Pathol. 37, 177-183.

Goldschmidt, M., Peña, L., Rasotto, R. and Zappulli, V. 2011. Classification and grading of canine mammary tumors. Vet. Pathol. 48(1), 117-131.

Gupta, K., Sood, N.K., Uppal, S.K., Mohindroo, J., Mahajan, S., Raghunath, M. and Singh, K. 2012. Epidemiological studies on canine mammary tumour and its relevance for breast cancer studies. IOSR J. Pharm. 2(2), 322-333.

Haga, S., Watanabe, O., Shimizu, T., Imamura, H., Iida, T., Makita, M. and Kajiwara, T. 1991. The clinical value of tissue carcinoembryonic antigen in breast cancer. Jpn. J. Surg. 21(3), 278-283.

Hawai, S.M., Al Zayer, M., Ali, M.M., Niu, Y., Al awad, A., Al jofan M., Al jarbou, A. and Al tuwijri, S. 2013. Dogs : active role model for cancer studies - a review. J. Can. Ther. 4, 989-495.

Hsu, S.M., Raine, L. and Fanger, H. 1981. Use of avidin-biotin Peroxidase complex (ABC) in immunoperoxidase techniques. J. Histochem. Cytochem. 29, 557-580.

Janschek, E., Kandioler-Eckersberger, D., Ludwig, C., Kappel, S., Wolf, B., Taucher, S. and Jakesz, R. 2001. Contralateral breast cancer: molecular differentiation between metastasis and second primary cancer. Breast Cancer Res. Treat. 67, 1-8.

Joensuu, K., Leidenius, M., Kero, M., Anderson, L.C., Horwitz, K.B. and Heikkila, P. 2013. ER, pR, HeR2 , Ki 67 and cK5 in early and late relapsing breast cancer- reduced cK5 expression in metastasis. Breast Cancer (Auckl). 7, 23-24.

Kumar, P., Paiya, R.V.S. and Madhu, B.P. 2010. Multiple mammary tumours in a bitch: analysis of mitotic index, AgNOR count and c-erbB2 expression status: a case report. Vet. Med. 55(12), 631-635.

Lana, S.E., Ruttemans, G.R. and Withrow, S.J. 2007. Tumors of the mammary gland. In: Small Animal Clinical Oncology. (Withrow, S.J., D.M. Vail, Eds.). Saunders, Elsevier. St. Louis, Missouri, pp: 619-636.

Lichtenbeld, H.C., Barendsz-Janson A.F. and Ven 
Essen, H. 1998. Angiogenic potential malignant and non-malignant human breast tissue in an in vivo angiogenesis model. Int. J. Cancer 77, 455-459.

Lillie, R.D. 1965. Histopathologic technic and practical histochemistry, $3^{\text {rd }}$ edition, McGraw-Hill Book Co., New York.

Misdorp, W., Else, R.W. and Hellemn, E. 1999. Definitions and explanatory notes. WHO histological classification of mammary tumors of the dog and cat. Washington: Armed Forces Institute of Pathology, pp: 18-27.

Misdorp, W. 2002. Tumors of the mammary gland. D.J. Mueten. (Ed.): Tumors in Domestic Animals. State University of California, pp: 575-606.

Mol, J.A. 2013. Comparative breast cancer research, lessons from companion animals. BMC Proc. 7, Suppl. 2:K9. doi: 10.1186/1753-6561-7-S2-K9.

Morris, J.S., Nixon, C., King, O.J.A., Morgan, I.M. and Philbey, A.W. 2009. Expression of top BP1 in canine mammary neoplasia in relation to histological type, Ki 67, ER $\alpha$ and p53. Vet. J. 179, 422-429.

Moulton, J.E., Taylor, D.O.N., Dorn, C.R. and Andersen, A.C. 1970. Canine mammary tumors. Pathol. Vet. 7(4), 289-320.

Mudholkar, V.G., Kawade, S.B. and Mashal, S.N. 2012. Histopathological study of neoplastic lesions of breast. Indian Med. Gazette 9, 353-364.

Nerurkar,V.R., Chitale, A.R., Jalnapurkar, B.V., Naik, S.N. and Lalitha, V.S. 1989. Comparative pathology of canine mammary tumors. J. Comp. Pathol. 101(4), 389-397.

Nowak, M., Madej, J.A. and Dziegiel, P. 2005. Correlation in the expression of HER2 receptor and Ki-67 antigen in mammary adenocarcinomas in bitches. Bull. Vet. Inst. Pulawy, 49(3), 337-342.

Peña, L., Gama, A., Goldschmidt, M.H., Abadie, J., Benazzi, C., Castagnaro, M., Díez, L., Gärtner, F., Hellmén, E., Kiupel, M., Millán, Y., Miller, M.A., Nguyen, F., Poli, A., Sarli, G., Zappulli, V. and de las Mulas, J.M. 2014. Canine Mammary Tumors: A Review and consensus of standard guidelines on epithelial and myoepithelial phenotype markers, HER2, and hormone receptor assessment using immunohistochemistry. Vet. Pathol. 51, 127-145.

Press, M.F., Bernstein. L. and Thomas, P.A. 1997. HER-2/neu gene amplification characterized by fluorescence in situ hybridization .J. Clin. Oncol. 15, 2894-2904.

Qiu, J., Kulkarni, S., Chandrasekhar, R., Rees, M.,
Hyde, K., Wilding, G. and Khoury, T. 2010. Effect of delayed formalin fixation on estrogen and progesterone receptors in breast cancer: A study of tthree different clones. Am. J. Clin. Pathol. 134(5), 813-819.

Queiroga, F.L., Raposo, T., Carvalho, M.S., Prada, J. and Pires, I. 2011. Canine mammary tumors as a model to study human breast cancer: most recent findings. In Vivo 25, 455-466.

Reddy, G.B.M., Kumar, P., Kumar, R., Pawaiya, R.V.S. and Ravindran, R. 2009. Histopathological classification and incidence of canine mammary tumours. Indian J. Vet. Pathol. 33, 152-155.

Sinn, H. and Kreipe, H. 2013. A brief overview of the WHO classification of breast tumors, 4th edition, focusing on issues and updates from the $3^{\text {rd }}$ edition. Breast Care 8, 149-154.

Sorenmo, K.U., Kristiansen, V.M., Cofone, M.A., Shofer, F.S., Been, A.M., Langeland, M., Mongel, C.M, Grondahl, A.M., Teige, J. and Goldschmidt, M.H. 2009. Canine mammary gland tumors: A histological continuum from benign to malignant; clinical and histological evidence. Vet. Comp. Oncol. 7(3), 162-172.

Stavros, A.T., Thickman, D., Rapp, C.L., Dennis, M.A., Parker, S.H. and Sisney, G.A. 1995. Solid breast nodules: use of sonography to distinguish between benign and malignant lesions. Radiology, 196(1), 123-134.

Sultan, F. and Ganaie, B. 2018. Comparative oncology: Integrating human and veterinary medicine. Open Vet. J. 8(1), 25-34.

Tavassoli, F.A. and Devilee, P. 2003. World Health Organization Classification of Tumors: Pathology and Genetics of Tumors of the Breast and Female Genital Organs. Vol. 5, IARC Press, Lyon, pp: 1415.

Webster, J.D., Miller, M.A., DuSold, D. and RamosVara, J. 2009. Effects of prolonged formalin fixation on diagnostic immunohistochemistry in domestic animals. J. Histoch. Cytochem. 57(8), 753-761.

Yang, W.Y., Liu, C.H., Chang, C.J., Lee, C.C., Chang, K.J. and Lin, C.T. 2006. Proliferative activity, apoptosis and expression of oestrogen receptor and Bcl-2 oncoprotein in canine mammary tumors. J. Comp. Pathol. 134, 70-79.

Zaha, D.C. 2014. Significance of immunohistochemistry in breast cancer. World J. Clin. Oncol. 5(3), 382. 